\title{
Considering what works: experiments in science communication
}

\section{Emma Weitkamp}

Abstract

Keywords
This issue of JCOM explores the question 'what works in science communication?' from a variety of angles, as well as focusing on the politically sensitive topic of climate change. In addition, the issue contains a set of commentaries that explore the sometimes conflicting roles of universities in science communication.

Environmental communication; Public understanding of science and technology; Science communication: theory and models

This issue of JCOM explores the question 'what works in science communication?' from a variety of angles, as well as focusing on the politically sensitive topic of climate change. While the rationales and purposes of science communication are many and varied, papers in this issue of JCOM consider how different presentations of astronomical images influence understanding, engagement and aesthetic appreciation amongst non-specialists [Smith et al., 2017]. Three papers consider facets of science communication in the polarised discourse on climate change in the US [see for example, Dunlap and McCright, 2015], Yeo et al. [2017] explore the impact of temperature on social media discussion of climate change and global warming, while Kahan [2017] and van der Linden, Leiserowitz and Maibach [2017] debate the value of consensus messaging, where communication focuses on highlighting the majority agreement of scientists on a topic that is perceived as controversial (e.g. 97\% of scientists agree that climate change is caused by humans).

Employing an online, experimental design, Smith et al. [2017] analyse the features of astronomy images that affect understanding, engagement and aesthetic appreciation amongst non-specialists. They find that images that are familiar ('what the public thinks objects from space should look like') were rated more appealing and easier to understand. However, they also note that there is scope to use more challenging or unusual images provided they are accompanied by explanatory text. Such text should include information on the colours used, as well as the size and location of the object.

Public use of the terms climate change and global warming are explored by Yeo et al. [2017] who find the terms are used in different contexts on Twitter. Climate change is associated with political and environmental discourses while global warming is used more often in the context of weather and energy. Comparing US regional weather events, Yeo et al. [2017] also found that use of the term 'global 
warming' was associated with extreme weather events and seasonality. This supports previous research that suggests in the US, at least, the term global warming is more associated with extreme weather events, while the term 'climate change' is perceived to be a more political construct. This reflects a range of other studies that have explored the ways that these terms are used by the public [e.g. Akerlof and Maibach, 2011] and how traditional media have covered climate change [e.g. Boykoff and Boykoff, 2004; Boykoff and Boykoff, 2007]. Yeo et al. argue that ' $\mathrm{t}$ ] his highlights a need for strategic use of these terms as they may influence public discourses of climate change.' [p. 17]

Finally, two papers Kahan [2017] and van der Linden, Leiserowitz and Maibach [2017], debate the value of consensus messaging in the context of climate change. Pearce et al. [2017] in a recent commentary argue that creative approaches are needed that allow 'inclusive and accessible' discussion of climate change policy and point to examples where uncomfortable bedfellows (such as the US Green Tea Party and Environmentalists) may support similar policies, but for widely different reasons. In the same issue, Cook [2017] argues that establishing (and communicating) that there is a scientific consensus is an important facet of climate change communication; noting that 'failure to address misconceptions about consensus enables the persistence of distractions that can delay substantive policy discussion'. While the debate between Kahan [2017] and van der Linden, Leiserowitz and Maibach [2017] is not entirely about the appropriateness of consensus messaging, focusing more directly on disagreements about the validity of the gateway belief model, ${ }^{1}$ these papers should be considered in the context of this wider debate. We leave the reader to consider the arguments put forward by both van der Linden et al. and Kahan about the gateway belief model and the wider role of consensus messaging. JCOM is happy to host debates of this nature that bring to the fore discussions about methodological approaches, particularly if they enable the wider community to engage in deeper discussion. Research is an alive and ever evolving activity and it is only through these open discussions that the community can develop. Such debates are an intrinsic aspect of a vibrant research community.

In addition to these research papers, the commentaries published in this issue of JCOM explore approaches to science communication within the higher education sector. Challenges presented by the increasing pressure on scientists and scientific institutions to publicise research findings are considered along with approaches to education in science communication. This collection seems particularly appropriate set against the research articles published here, most of which explore, in a range of different ways, 'what works' in science communication practice.

\footnotetext{
${ }^{1}$ The Gateway Belief model proposes a means of testing whether consensus messaging affects people's opinions and attitudes. The model posits that public perceptions of the agreement between scientists on controversial issues such as climate change and GMOs, influences their opinions and attitudes towards these scientific topics, thereby acting as a 'gateway' cognition.
} 
Akerlof, K. and Maibach, E. W. (2011). 'A rose by any other name... ?: What members of the general public prefer to call "climate change"'. Climatic Change 106 (4), pp. 699-710. DOI: 10.1007/s10584-011-0070-4.

Boykoff, M. T. and Boykoff, J. M. (2004). 'Balance as bias: global warming and the US prestige press'. Global Environmental Change 14 (2), pp. 125-136. DOI: $10.1016 / j$.gloenvcha. 2003.10.001.

- (2007). 'Climate change and journalistic norms: A case-study of US mass-media coverage'. Geoforum 38 (6), pp. 1190-1204. DOI: $10.1016 / \mathrm{j}$.geoforum. 2007.01 .008 .

Cook, J. (2017). 'Response by Cook to "Beyond Counting Climate Consensus"'. Environmental Communication 11 (6), pp. 733-735. DOI: $10.1080 / 17524032.2017 .1377095$.

Dunlap, R. E. and McCright, A. M. (2015). ‘Challenging Climate Change'. In: Climate Change and Society, pp. 300-332. DOI: $10.1093 /$ acprof : oso/9780199356102.003.0010.

Kahan, D. (2017). 'The "Gateway Belief" illusion: reanalyzing the results of a scientific-consensus messaging study'. JCOM 16 (5), A03. URL: https://jcom.sissa.it/archive/16/05/JCOM_1605_2017_A03.

Pearce, W., Grundmann, R., Hulme, M., Raman, S., Kershaw, E. H. and Tsouvalis, J. (2017). 'Beyond Counting Climate Consensus'. Environmental Communication 11 (6), pp. 723-730. DOI: 10.1080/17524032.2017.1333965.

Smith, L., Arcand, K., Smith, R., Bookbinder, J. and Smith, J. (2017). 'Capturing the many faces of an exploded star: communicating complex and evolving astronomical data'. JCOM 16 (5), A02.

van der Linden, S., Leiserowitz, A. and Maibach, E. (2017). 'Gateway illusion or cultural cognition confusion?' JCOM 16 (5), A04. URL: https://jcom.sissa.it/archive/16/05/JCOM_1605_2017_A04.

Yeo, S., Handlos, Z., Karambelas, A., Su, L. Y.-F., Rose, K., Brossard, D. and Griffin, K. (2017). 'The influence of temperature on \#ClimateChange and \#GlobalWarming discourses on Twitter'. JCOM 16 (5), A01.

Author

Emma Weitkamp is an Associate Professor in Science Communication and Co-Director of the Science Communication Unit at the University of the West of England, Bristol where she teaches on an MSc in Science Communication and provides training in science communication for practitioners and $\mathrm{Ph} . \mathrm{D}$. students. Emma is also Editor in Chief of JCOM. E-mail: Emma.Weitkamp@uwe.ac.uk.

\section{How to cite}

Weitkamp, E. (2017). 'Considering what works: experiments in science communication'. JCOM 16(05), E. 